\title{
COMPETÊNCIAS ADQUIRIDAS DURANTE O CURSO DE GRADUAÇÃOO EM ADMINISTRAÇÃO DE EMPRESAS NA ÓTICA DOS ALUNOS FORMANDOS: UM ESTUDO EM CINCO INSTITUIÇÕES DE ENSINO SUPERIOR
}

SKILLS ACQUIRED DURING THE BUSINESS ADMINISTRATION UNDERGRADUATE COURSE AS PER THE STUDENTS' PERCEPTION: A STUDY IN FIVE HIGHER EDUCATION INSTITUTIONS

MARTA FABIANO SAMBIASE LoMBARdi (martasl@ mackenzie.br) UNIVERSIDADE PRESBITERIANA MACKENZIE

\section{LUCIANA TRAVERSO}

UNIVERSIDADE FEDERAL DE SANTA MARIA

\section{RAMON SILVA LEITE}

Pontifícia Universidade Católica de Minas Gerais

Francisval de Melo Carvalho

UNIVERSIDADE FEDERAL DE LAVRAS

\section{Abrão Caro}

UNIVERSIDADE PRESBITERIANA MACKENZIE

\section{RESUMO}

Considerando as diretrizes curriculares para os cursos de Administração, este estudo procura compreender se as Instituições de Ensino Superior (IES), na percepção dos alunos formandos, têm conseguido desenvolver os conhecimentos, habilidades e atitudes sugeridas por tais diretrizes ao longo do curso de graduação. Para tanto, foi aplicada uma pesquisa aos acadêmicos do último ano de graduação em Administração de cinco diferentes IESs, localizadas nos estados de Minas Gerais, Santa Catarina e São Paulo. A pesquisa tipo exploratório-descritivo, com abordagem quantitativa, utilizou estatística descritiva e fatorial exploratória para comparar os grupos sugeridos pelas diretrizes básicas e pela percepção dos alunos. Os resultados apontam que a percepção dos formandos é mais genérica do que a classificação de competências das Diretrizes Curriculares Nacionais (DCN), resultando em quatro fatores, nomeados de capacidade de gestão, habilidade relacional, conhecimento e orientação. $\mathrm{O}$ agrupamento em quatro fatores sugere que os oito grupos de competências e habilidades que as DCN prevê sejam possíveis de serem reveladas pelos cursos de graduação em Administração não são reconhecidas pelos discentes.

Palavras-chave: competência; diretrizes curriculares; graduação; administração de empresas. 
ABSTRACT

By considering the curriculum guidelines for Business Administration courses, this study seeks to understand whether the Institutions of Higher Education, as per the perception of students, have been able to develop the knowledge, skills and attitudes suggested by such guidelines throughout the undergraduate course. With this purpose, a survey was carried out with students of the last year of Business Administration graduate courses from five different Higher Education Institutions located in the states of Minas Gerais, Santa Catarina and São Paulo. The exploratory-descriptive research with quantitative approach used descriptive and factorial exploratory statistics to compare groups suggested by the basic guidelines and students' perceptions. The results indicate that the perception of students is more generic than the rank of powers of the National Curriculum Guidelines (NCG), resulting in four factors, named management capacity, relational skills, knowledge and guidance. The grouping into four factors may suggest that the expectation of the NGC, divided into eight groups, is not perceived by students, or, not yet recognized by them.

Keywords: competence; curriculum guidelines; undergraduate education; business administration.

\section{INTRODUÇÃO}

A educação superior tem mostrado habilidade para transformar e induzir mudanças na sociedade, por ser o local para a formação da mão de obra de trabalho especializada e, também, de profissionais responsáveis para o desenvolvimento econômico e social.

Rápidas e profundas transformações socioeconômicas e tecnológicas têm ocorrido nos últimos anos, acarretando novas exigências aos profissionais que já exercem suas funções, mas também aos que estão sendo capacitados pelas instituições de ensino superior. Estas mudanças são complexas e exigem que os profissionais sejam capazes de dominar novas tecnologias, utilizar racionalmente os recursos, tomar decisões em situações de pressão e risco, inovar, entre tantos outros desafios apresentados no mercado de trabalho. São ainda exigidas dos profissionais, articulações eficientes de conhecimentos, habilidades e 
atitudes que o campo de atuação demanda. Corroborando essa ideia, Coêlho (1998, p. 15) relata:

Os empregadores exigem cada vez mais pessoas críticas, criativas, flexíveis, bem informadas, interessadas em seu crescimento pessoal e profissional, com uma boa compreensão da empresa e de todo o processo de trabalho, redação própria e fluência verbal em pelo menos duas línguas, bons conhecimentos em informática e capazes de, com inteligência e rapidez, resolver problemas e responder aos desafios que surgem a cada momento.

Nesse contexto de mudanças e novas exigências requeridas aos profissionais, foi aprovada, em 1995, a nova LDB - Lei das Diretrizes e Bases da Educação, que contempla a proposição de diretrizes para os cursos de graduação. Atendendo a essa nova orientação da política para o ensino superior, o Conselho Nacional de Educação, pela Resolução $n^{\circ} 4$, de 13 de julho de 2005, institui as Diretrizes Curriculares Nacionais (DCN) do Curso de Graduação em Administração, em nível de bacharelado. Com isso foi estabelecido o conjunto mínimo de competências e habilidades que os futuros profissionais em Administração devem desenvolver ao longo dos cursos superiores.

Considerando a existência dessas diretrizes curriculares para os cursos de Administração, bem como as exigências atuais do mercado de trabalho, este estudo procurou responder a seguinte pergunta: as instituições de ensino superior (IES), na percepção dos alunos formandos, têm conseguido desenvolver os conhecimentos, habilidades e atitudes sugeridas pelas diretrizes curriculares, durante o curso de graduação de Administração?

Para responder a esta questão foi desenvolvida uma pesquisa com acadêmicos do último ano do curso de graduação de Administração de Empresas de cinco diferentes IES, localizadas nos estados de Minas Gerais, Santa Catarina e São Paulo. O estudo identificou a percepção dos alunos sobre as competências adquiridas durante o curso de graduação. Espera-se que tais informações ofereçam subsídios para a discussão de aspectos relativos à formação dos administradores em cursos de graduação frente às diretrizes definidas pela DCN.

O trabalho está estruturado em cinco partes fundamentais, iniciando-se por essa introdução. Na segunda, é feita uma revisão bibliográfica de assuntos relativos às competências e aos cursos de graduação em administração de empresas. Na terceira, é apresentada a metodologia utilizada na pesquisa; na quarta, são apresentados os 
resultados obtidos, bem como a análise destas informações; e, na última parte, são apresentadas as considerações finais e sugestões para a continuidade de pesquisa neste tema.

\section{REFERENCIAL TEÓRICO}

Visa melhor encaminhar este estudo e apresentar a teoria que serviu para orientar a realização da pesquisa. Neste sentido, são apresentadas as diretrizes que têm direcionado o desenho dos cursos de graduação em Administração de Empresas no Brasil, bem como uma reflexão de conceitos acerca do tema competências.

\section{O ENSINO DE ADMINISTRAÇÃO NO BRASIL}

Para compreender o ensino de Administração, objeto de estudo deste trabalho, é importante considerar os aspectos históricos referentes ao seu desenvolvimento. Nicolini (2002, p.1) comenta que:

A história dos cursos superiores de Administração no Brasil começa logo no início do século, simultaneamente com um longo processo de definição sobre quais seriam as fronteiras do campo do saber administrativo. Durante mais de seis décadas, o ensino das ciências administrativas se confundiu com o ensino das Ciências Econômicas, até a definição do currículo mínimo do curso de graduação em Administração.

No mesmo trabalho, Nicolini (2002) faz uma consistente revisão sobre o processo de consolidação do ensino de Administração no Brasil, relatando desde o período em que a educação era privilégio reservado para poucos e não era prioridade do governo, até o início do processo de consolidação de cursos na área. O autor, no entanto, explica que essa expansão e consolidação dos cursos coincidem com o "milagre econômico" que abriu grande campo para os bacharéis em administração; muito dessa demanda foi atendida por faculdades isoladas e privadas que, na maioria das vezes, estavam desvinculadas do processo de construção científica.

O governo, preocupado com a qualidade do ensino, cria a Lei de Diretrizes e Bases da Educação Nacional - LDB, que, por sua vez, estabelece o Conselho Federal de Educação. Uma das atribuições do Conselho Federal de Educação é fixar os conteúdos mínimos e a duração 
dos cursos superiores destinados à formação de pessoal cujas profissões estejam regulamentadas em lei, que é o caso da Administração.

Inicialmente a estruturação do currículo mínimo pela legislação foi bastante rígida, deixando em segundo plano até mesmo os processos pedagógicos e as características regionais onde os cursos de graduação estavam inseridos. Na segunda metade da década de 1990, o Brasil vê a instituição da nova Lei de Diretrizes e Bases da Educação Nacional, que objetivava regulamentar a educação nacional nas suas diversas modalidades. Essa lei representou um avanço para a educação brasileira e, apesar de implantada há mais de uma década, algumas possibilidades por ela previstas foram pouco utilizadas pela educação brasileira, como por exemplo, a efetiva flexibilidade e o aproveitamento de estudos extracurriculares. De acordo com essa lei, para a União fica a responsabilidade de baixar normas gerais sobre os cursos de pósgraduação e de graduação, enquanto a determinação dos currículos dos cursos e programas, observando as diretrizes gerais pertinentes, compete às universidades.

Surgem então as Diretrizes Curriculares Nacionais (DCN) dos cursos de graduação, que é um documento com as referências para que as Instituições de Ensino Superior (IES) se baseiem na elaboração dos currículos dos cursos que oferecem. Tais diretrizes permitem que as IES possam criar propostas de formação diferenciada, definindo o perfil profissional que desejam formar.

Com base nas experiências em docência, nas pesquisas realizadas e observando tendências educacionais, o Conselho Nacional de Educação elaborou novas Diretrizes Curriculares Nacionais do curso de graduação em Administração, que prevê, em seu artigo $4^{\circ}$, que os cursos de graduação em Administração devem possibilitar a formação profissional que revele, pelo menos, as seguintes competências e habilidades, divididas em oito grupos:

I - Reconhecer e definir problemas, equacionar soluções, pensar estrategicamente, introduzir modificações no processo produtivo, atuar preventivamente, transferir e generalizar conhecimentos e exercer, em diferentes graus de complexidade, o processo da tomada de decisão;

II - Desenvolver expressão e comunicação compatíveis com o exercício profissional, inclusive nos processos de negociação e nas comunicações interpessoais e intergrupais; 
III - Refletir e atuar criticamente sobre a esfera da produção, compreendendo sua posição e função na estrutura produtiva sob seu controle e gerenciamento;

IV - Desenvolver raciocínio lógico, crítico e analítico para operar com valores e formulações matemáticas, presentes nas relações formais e causais entre fenômenos produtivos, administrativos e de controle, bem assim expressando-se de modo crítico e criativo diante dos diferentes contextos organizacionais e sociais;

V - Ter iniciativa, criatividade, determinação, vontade política e administrativa, vontade de aprender, abertura às mudanças e consciência da qualidade e das implicações éticas do seu exercício profissional;

VI - Desenvolver a capacidade de transferir conhecimentos da vida e da experiência cotidianas para o ambiente de trabalho e do seu campo de atuação profissional, em diferentes modelos organizacionais, revelando-se profissional adaptável;

VII - Desenvolver capacidade para elaborar, implantar e consolidar projetos em organizações; e

VIII - Desenvolver capacidade para realizar consultoria em gestão e administração, pareceres e perícias administrativas, gerenciais, organizacionais, estratégicos e operacionais (CNE, 2005, p. 2).

É institucionalizada então, no ensino superior de Administração, a formação profissional que busca desenvolver as competências e habilidades necessárias aos administradores. Considerando-se a perspectiva dos acadêmicos, no entanto, embora seja esperado que o aluno que conclua o curso de graduação apresente tais competências e habilidades, alguns estudos vêm apontando obstáculos ao alcance destas metas. Acompanhando as discussões que se estabeleceram inclusive no âmbito da Associação Nacional dos Cursos de Graduação em Administração - ANGRAD, é possível perceber que as escolas apresentam dificuldades na adoção e utilização do modelo de competências na organização e implantação de seus projetos pedagógicos. Dessa forma, questões referentes à reformulação dos projetos pedagógicos dos cursos de graduação em Administração têm sido enfatizadas em diferentes oportunidades (GODOY et al., 2005), o que torna a discussão sobre a aquisição efetiva das competências sugerida nas diretrizes, pertinente para a compreensão do fato e para a consequente implantação de ações, ou manutenção, das atividades desenvolvidas pelas IES.

Como a pesquisa aqui proposta está centrada na formação dos administradores, frente às competências e habilidades sugeridas pelas 
DCN, torna-se necessária a compreensão do significado de competência, para identificar se os projetos pedagógicos dos cursos de Administração têm conseguido desenvolver tais habilidades em seus alunos.

\section{REFLEXÃo de CONCEITOS DE COMPETÊNCIAS}

Prahalad e Hamel (1995) sugerem que, com as mudanças das fronteiras de mercado, há necessidade de repensar a corporação, desenvolvendo uma arquitetura estratégica que estabeleça objetivos para a formação de competências.

Em meados da década de 1980, surgiu a temática das competências como modelo de gestão de Recursos Humanos, em resposta às mudanças no mundo do trabalho, sendo competência entendida como uma "inteligência prática das situações, que se apóia em conhecimento adquirido e o transforma, à medida que a diversidade das situações aumenta" (ZARIFIAN, 2003, p.137). Levy-Leboyer (1997) afirma que as competências estão vinculadas tanto a uma tarefa quanto a um conjunto de atividades e são saberes articulados, realizados de maneira internalizada, uma vez que o indivíduo utiliza este saber no momento adequado, sem ter a necessidade de consultar regras básicas ou perguntar sobre qual conduta adotar. Para essa autora, contudo, justamente por tratar-se de diferentes saberes tácitos, é difícil descrever e, por consequência, compreender, as características reais das competências.

Sandberg (1994), numa perspectiva mais ampla que evidencia a competência também como atributo das organizações, apresenta estudos que tratam da apreensão de competências pelos gestores e que dividem as competências em dois níveis: coletivo e individual. No nível coletivo, compõem um conjunto de habilidades, tecnologias e capacidades presentes na empresa e que são essenciais para a manutenção de seu sucesso, configurando-se, portanto, como a alma da organização. Prahalad e Hamel (1995) cunharam o termo competências essenciais e este tem sido amplamente utilizado nas organizações e na academia.

Doz (1994) afirma que as competências no nível individual são compostas de três dimensões - Conhecimentos, Habilidades e Atitudes (CHA) - e estas são acrescidas de interação e experiência. Doz (1994) e Fleury e Fleury (2001) relacionam competências individuais à cognição e, neste caso, percepção, experiência e emoção são ingredientes do processo. A dimensão habilidade está relacionada à capacidade de transformar conhecimento em ação. Por fim, a atitude, para Fleury e 
Fleury (2001, p.35), está relacionada a "um saber agir responsável e reconhecido, que implica mobilizar, integrar, transferir conhecimentos, recursos, habilidades, que agreguem valor econômico à organização e valor social ao indivíduo".

A competência individual também é definida por Perrenoud (1999, p. 7) como a "capacidade de agir eficazmente em um determinado tipo de situação, apoiada em conhecimentos, mas sem limitar-se a eles". Nesse sentido, a competência utiliza, integra e mobiliza conhecimentos relevantes para a solução de problemas organizacionais. A competência individual está associada "à perícia e supõe também atitudes e posturas mentais, curiosidade, paixão, busca de significado, desejo de tecer laços, relação com o tempo, [...] cautela e audácia, que nascem tanto da formação como da experiência" (PERRENOUD, 1999, p. 9, tradução nossa). A competência se constitui, portanto, num "saber fazer", que, segundo o mesmo autor, designa uma representação procedimental, ou seja, a direção para ação sendo precedida de um treinamento intensivo capaz de produzir gestos que se confundem com uma segunda natureza. Nesse sentido, mede-se a competência do sujeito por meio da ação como um exercício efetivo da capacidade. Outro aspecto relevante das competências individuais é o seu caráter transversal que lhes permite enfrentar conjuntos de situações simples ou complexas.

Ruas (2001) sugere a necessidade de repensar os nexos entre formação e competências, uma vez que os treinamentos por si só não dão conta de explicar as melhorias que ocorrem nas organizações, aspecto este corroborado por Zarifian (2001), que denomina as competências adquiridas no processo educativo de "competências de fundo" ou "competências recursos". Este autor considera que o termo competências utilizado nos sistemas formativos não tem exatamente o mesmo sentido quando do seu emprego pela área empresarial, pois as ações de formação não são marcadas pela relação salarial nem podem se comprometer em garantir uma preparação que esteja pautada nas responsabilidades, controles e sanções que caracterizam os sistemas produtivos. Tal visão mostra outra perspectiva sobre as competências aplicadas ao ensino de graduação, já que evidencia existirem características peculiares que devem ser observadas a fim de efetivamente serem estimuladas e desenvolvidas nos indivíduos. Nesse sentido, há uma relevante consideração pautada por Godoy et al. (2005, p. 7) quando explicam que:

É importante destacar que a leitura da literatura sobre competências aponta para um ponto comum entre os autores que é a derivação das competências com base no conjunto de conhecimentos, habilidades 
e atitudes esperadas das pessoas. Como se pode detectar este tripé está presente nos artigos teóricos, nos artigos de pesquisa empírica, nos artigos que examinam a questão no âmbito das empresas, assim como nos que buscam refletir e analisar como a noção de competência tem sido usada pelos processos educativos formais e não formais responsáveis pelo desenvolvimento dos indivíduos em diferentes níveis.

Desta forma, Godoy e Forte (2007, p. 59) explicam que há forte preocupação com a formação, principalmente com a formação profissional; promovendo novo impulso com a adoção do conceito de competência na condição de orientador das decisões curriculares que norteiam a elaboração dos projetos pedagógicos dos cursos. Nicolini (2002), citado em Perrenoud (2000) e Zarifian (2001, 2003), explica que as instituições de ensino devem criar propostas diferenciadas de formação, elaborando, com base no conjunto de competências a ser desenvolvida durante a graduação, o perfil profissional que desejam formar em seus alunos.

As IES que oferecem cursos de graduação em Administração precisam, portanto, se preocupar com as estratégias de aprendizagem de modo a permitir o desenvolvimento das habilidades, atitudes e conhecimento especificados nas diretrizes curriculares e de acordo com o projeto pedagógico de seus respectivos cursos. Desta forma, elas promoveriam a aquisição pelos futuros Administradores das competências requeridas pela sociedade.

Percebendo a relevância e crescente valorização das competências também para o ensino, alguns estudos na área da administração vêm sendo elaborados com esta perspectiva. Duas pesquisas analisam o papel das competências na perspectiva das IES (NUNES; BARBOSA, 2003; NUNES; FERRAZ; BARBOSA, 2004), outros dois estudos analisam as competências pela percepção dos alunos do último ano de cursos de graduação (GODOY; FORTE, 2007; GODOY et al., 2009), e outra pesquisa analisa a percepção dos egressos em relação às competências adquiridas ao longo da graduação (BITENCOURT; KLEIN, 2007).

Nunes e Barbosa (2003) analisaram a experiência de duas universidades - uma pública, outra privada - visando conhecer como foi adotada a lógica das competências no currículo do curso de graduação em Administração. A pesquisa identificou que, em ambos os casos, o levantamento das competências requeridas foi estruturado basicamente nas recomendações do MEC. Além disto, foi identificado também que existe a preocupação com os dois currículos analisados em possibilitar 
aos alunos uma formação que contemple o núcleo profissionalizante, somado aos aspectos mais amplos, voltados para o desenvolvimento da cidadania. Contudo, a pesquisa aponta que:

Uma rápida análise das propostas demonstra com certa clareza que existe um descompasso entre o sentido estratégico da formulação de competências e sua aplicabilidade cotidiana. Ou seja, entre a intenção e aplicação não foi observada maior concatenação. Isso significa dizer que as questões operacionais assumem lugar de destaque, na medida em que a preocupação encontra-se fixada no regimento definido pelo MEC. E acaba por se traduzir em ajustes pontuais e pouco efetivos quanto ao constructo necessário que um modelo de competências exige (NUNES; BARBOSA, 2003. p. 14)

Nunes, Ferraz e Barbosa (2004) procuraram investigar como a noção de competências vem sendo utilizada nas estruturas curriculares de graduação em Administração de oito Instituições de Ensino Superior (IES) localizadas na região metropolitana de Belo Horizonte. A pesquisa constatou que três das faculdades pesquisadas demonstraram pouco entendimento acerca da noção de competências. Os autores concluíram com a pesquisa que, de maneira geral, as faculdades apresentam um comportamento tímido no que concerne às suas ações para a adequação às exigências do Ministério da Educação, revelando que a utilização do conceito de competências em educação, especificamente na área da Administração, requer amadurecimento.

Godoy e Forte (2007), por exemplo, identificaram quatro grupos de competências desenvolvidas em alunos que cursavam o último ano de graduação em Administração, sendo elas: Competência Social (referindose à capacidade de respeitar as pessoas); Competência Solução de Problemas (relacionada à identificação de problemas e desenvolvimento de soluções, visando gerar resultados); Competência Técnico-Profissional (envolvendo a capacidade de realizar tarefas e atividades de consultoria); e Competência de Comunicação (relativa à capacidade de manifestação de ideias de modo claro e objetivo).

Outra pesquisa, desenvolvida por Godoy et al. (2009) com alunos do último ano do curso de Administração, identificou, com base no modelo proposto por Cheetam e Chivers (1998 apud GODOY et al., 2009) que para os alunos pesquisados as competências adquiridas estão organizadas em quatro dimensões, a saber: Competência Social (capacidade de aperfeiçoamento contínuo, adaptação, respeitar o próximo, autocrítica, julgar e responsabilidade social); Competência Solução de 
Problemas (capacidade de resolução de problemas, pensar estrategicamente, realizar melhoria de processos, transferir e aplicar conhecimentos, tomar decisões e antever); Competência TécnicoProfissional (capacidade de buscar soluções criativas e inovadoras, desenvolver projetos, desenvolver consultoria, diagnosticar e emitir parecer técnico/gerencial); e Competências Básicas (comunicação, análise, raciocínio lógico e reflexão), esta última influenciando as três primeiras. Esta pesquisa identificou que a competência de ética e valores não foi identificada nos resultados do campo investigado, destacando a necessidade de estudos futuros referentes a essa competência no âmbito da Administração e das organizações.

Bitencourt e Klein (2007), inspiradas no trabalho de Godoy et al. (2005), pesquisaram as percepções de alunos egressos do curso de graduação em Administração. Esta pesquisa identificou seis competências percebidas pelos egressos deste curso: Competências de Ética e Valores, refere-se aos princípios éticos e morais; Competência de Solução de Problemas - busca do pensar estrategicamente na solução de problemas; Competência de Autodesenvolvimento - promover espírito investigativo para o aperfeiçoamento; Competências Técnico-Profissionais - obter reconhecimento por meio de consultoria, pareceres, perícias e implantação de projetos; Competência de Relacionamento Interpessoal e Comunicação - vislumbra o relacionamento com diferentes níveis hierárquicos; Competência de Raciocínio Lógico e Analítico - refere-se à aplicação de conhecimento técnico de forma lógica e analítica.

É possível verificar que os estudos empíricos deste campo apontam para um contexto no qual os cursos de administração das instituições de ensino pesquisadas não apresentam projetos pedagógicos estruturados com o objetivo de promover, de maneira sistematizada, o desenvolvimento das competências previstas nas diretrizes curriculares destes cursos. Na perspectiva dos alunos e egressos, no entanto, observase, pelas pesquisas realizadas, que as competências de Solução de Problemas, Técnico Profissional e Comunicação, são entendidas pelos acadêmicos como desenvolvidas ao longo do curso. Em menor proporção, aparecem como tendo sido desenvolvidas pelos alunos ao longo do curso as competências: Social, Autodesenvolvimento e Raciocínio Lógico. A pesquisa de Godoy e Forte (2007) identificou que o aprendizado de tarefas e atividades de consultoria e a emissão de pareceres e perícias administrativas, gerenciais, organizacionais, estratégicas e operacionais não são percebidos pelos egressos como competências desenvolvidas ao longo do curso, embora estas estejam presentes nas diretrizes curriculares 
do curso de Administração. A competência relacionada aos Valores é percebida pelos egressos de um grupo pesquisado como tendo sido desenvolvida ao longo do curso na pesquisa de Bitencourt e Klein (2007), mas este resultado não se repetiu em Godoy et al. (2009). Talvez esta diferença seja decorrente da vivência prática, possivelmente assegurada pela inclusão destes alunos no mercado de trabalho, demandando, desta forma, atitudes que requeiram a aplicação das atitudes éticas nas atividades laborais dos sujeitos pesquisados.

Os estudos de Nunes e Barbosa (2003); Nunes, Ferraz e Barbosa (2004), Godoy e Forte (2007), Bitencourt e Klein (2007) e Godoy et al. (2009) analisam o desenvolvimento de competências ao longo dos cursos de graduação em Administração sob óticas variadas, no entanto, nenhum buscou o alinhamento entre as competências desenvolvidas segundo a percepção dos alunos formandos e o demandado pela DCN.

\section{Procedimentos Metodológicos}

Com base nas orientações de formação de competências das DCNs para os cursos de graduação em Administração de Empresas, foi desenvolvido um questionário e respondido pelos alunos formandos de 5 IES brasileiras. Esta pesquisa, tipo exploratório-descritivo, buscou capturar a percepção dos discentes egressos e compará-la com as DCNs.

Como desenho mais apropriado para a presente pesquisa, optou-se por um survey interseccional, em que os dados são tratados em um único momento, de uma amostra selecionada para descrever a relação entre variáveis em uma população na mesma ocasião (BABBIE, 1999). A coleta dos dados foi realizada por meio de questionários que foram preenchimentos pelos respondentes e foram aplicados na sala de aula, no período de aula. $\mathrm{O}$ universo da pesquisa foi constituído pelos alunos do sétimo e oitavo períodos, ou seja, do último ano do curso, regularmente matriculados no curso de Administração das IES analisadas.

A amostra por conveniência foi formada por 289 alunos, sujeitos da pesquisa, que estavam presentes em sala no período da pesquisa e responderam o questionário. Os dados foram obtidos por meio da aplicação de um questionário estruturado, organizado em dois blocos: no primeiro, composto por sete questões, solicitava-se um conjunto de informação destinado à caracterização dos sujeitos. O segundo bloco continha 22 itens, baseados nas competências sugeridas pelo MEC e que foram respondidos por meio de uma escala tipo Likert de cinco pontos - 
Discordo Totalmente (0) a Concordo Totalmente (4); para o questionário da pesquisa (Apêndice $\mathrm{A}$ ), onde o item 8 corresponde às competências das DCNs, desordenadamente apresentadas, ao invés de ordenadas por grupos como na Tabela 4.

Inicialmente foram identificados dados ausentes e outliers univariados e multivariados. Depois foram elaboradas tabelas de frequência e, em seguida, foi realizada análise fatorial exploratória para identificação do agrupamento dos dados coletados. Por fim, foi realizada regressão logística para melhor compreender a relação entre variáveis.

\section{APRESEnTAÇÃo das CinCo IES OBJETOS dA PESQUiSA}

Para a realização do estudo, foram pesquisadas cinco Instituições de Ensino Superior, sendo duas localizadas no Estado de São Paulo, uma na capital e denominada neste trabalho de IES 5; e outra no interior centrooeste, denominada aqui IES 4. Outras duas IES estão localizadas no Estado de Minas Gerais, ambas no interior em distintas cidades, denominadas IES 3 e IES 2; por fim, a IES 1, está localizada no interior do Estado de Santa Catarina. Visando apresentar características das IES pesquisadas, foi disponibilizada no Quadro 1 informação referente às constituições jurídicas, número total de alunos, tempo e período de oferta do curso de Administração, número de alunos no curso de Administração e nos dois últimos semestres, bem como a quantidade de respondentes da pesquisa.

Quadro 1: Apresentação das cinco IES objeto do estudo

\begin{tabular}{|c|c|c|c|c|c|}
\hline & $\begin{array}{c}\text { IES 1 } \\
\text { SC }\end{array}$ & $\begin{array}{c}\text { IES 2 } \\
\text { MG }\end{array}$ & $\begin{array}{c}\text { IES 3 } \\
\text { MG }\end{array}$ & $\begin{array}{c}\text { IES } 4 \\
\text { SP }\end{array}$ & $\begin{array}{c}\text { IES } 5 \\
\text { SP }\end{array}$ \\
\hline Constituição jurídica & $\begin{array}{l}\text { Fundação } \\
\text { universitária }\end{array}$ & $\begin{array}{c}\text { Privada } \\
\text { Confessional }\end{array}$ & Federal & $\begin{array}{l}\text { Privada } \\
\text { Familiar }\end{array}$ & $\begin{array}{c}\text { Privada } \\
\text { Confessional }\end{array}$ \\
\hline $\begin{array}{l}\text { Quantidade de alunos totais } \\
\text { da IES }\end{array}$ & 5.342 & 2.300 & 2.591 & 1.200 & 28.400 \\
\hline $\begin{array}{l}\text { Tempo de oferta do curso de } \\
\text { Administração }\end{array}$ & 34 anos & 6 anos & 11 anos & 6 anos & 29 anos \\
\hline $\begin{array}{l}\text { Período em que o curso de } \\
\text { Administração é ofertado }\end{array}$ & Noite & Noite & Dia & Noite & Dia e noite \\
\hline $\begin{array}{l}\text { Quantidade de alunos no } \\
\text { curso Administração }\end{array}$ & 226 & 376 & 219 & 350 & 525 \\
\hline $\begin{array}{l}\text { Quantidade de alunos } \\
\text { respondentes da pesquisa }\end{array}$ & 36 & 65 & 26 & 65 & 97 \\
\hline
\end{tabular}

Examinando o Quadro 1, percebe-se que cada IES possui uma constituição jurídica distinta, o que retrata a expansão e diversidade dos 
cursos de graduação, especialmente o de Administração, no Brasil da última década. Algumas IES são novas e a localização da maioria nos interiores dos Estados de SP, MG e SC, refletindo a configuração de expansão geográfica e interiorização cultural e econômica. Praticamente dois terços dos respondentes $(75,4 \%)$ estavam matriculados no sétimo semestre do curso e o outro um terço $(24,6 \%)$ estava matriculado no oitavo e último semestre do curso.

\section{Apresentação e Análise dos Dados da Pesquisa}

A apresentação dos resultados obtidos inicia-se com a identificação dos respondentes, os quais são classificados com base em diferentes critérios. Em seguida, são analisados os resultados obtidos, baseados na análise descritiva dos dados, finalizando esta etapa com informações relativas à análise fatorial realizada.

\section{Descrição da Amostra}

A caracterização da amostra estabelece-se com base em dados classificatórios dos respondentes relativos à: gênero, faixa etária, motivo de escolha do curso, tipo de instituição de ensino em que cursou o ensino médio, semestre em que está matriculado, realização de cursinho preparatório e, finalmente, instituição de ensino.

Tabela 1: Distribuição dos respondentes por gênero e faixa etária

\begin{tabular}{cccccccccccc}
\hline \multicolumn{4}{c}{ Gênero } & \multicolumn{10}{c}{ Faixa etária } \\
\hline \multicolumn{2}{l}{ Masculino } & \multicolumn{2}{c}{ Feminino } & \multicolumn{2}{c}{ Menos de 20} & 21 & a 25 & 26 a 30 & \multicolumn{2}{c}{ Acima de 31 } \\
\hline Freq & $\%$ & Freq & $\%$ & Freq & $\%$ & Freq & $\%$ & Freq & $\%$ & Freq & $\%$ \\
\hline 163 & 56,4 & 126 & 43,6 & 1 & 0,3 & 237 & 82 & 29 & 10 & 22 & 7,6 \\
\hline
\end{tabular}

Conforme a Tabela 2, a maioria dos respondentes (82\%) tem entre 21 e 25 anos de idade e $78,6 \%$, exercem atividade remunerada em período parcial ou integral.

Tabela 2: Exercício de atividade remunerada

\begin{tabular}{lcc}
\hline Atividade Remunerada & Número & $\mathbf{\%}$ \\
\hline Não exerce & 43 & 15,1 \\
\hline Parcial (até 30 horas) & 93 & 32,7 \\
\hline Integral (31hs ou mais) & 130 & 45,9 \\
\hline Trabalho eventual & 18 & 6,3 \\
\hline Total & 289 & 100 \\
\hline
\end{tabular}

$\mathrm{Na}$ amostra estudada, o principal motivo para a escolha do curso de Administração de Empresas foi a possibilidade de aumentar as 
oportunidades no mercado de trabalho, para 38,9\% (Tabela 3). Dos respondentes, verifica-se uma semelhança quase simétrica entre aqueles que cursaram o ensino médio em escola pública $(51,2 \%)$ e aqueles que cursaram o ensino médio em escola particular $(48,8 \%)$. Na classificação relativa à realização de cursinho preparatório para ingresso no curso, verificou-se que $46,3 \%$ dos respondentes realizaram esse tipo de curso, enquanto os demais $53,7 \%$ não.

Tabela 3: Motivo para a escolha do curso

\begin{tabular}{lcc}
\hline Motivo da Escolha do Curso & Número & \% \\
\hline Relação com o trabalho atual & 66 & 23,3 \\
\hline Aptidão pessoal & 81 & 28,6 \\
\hline Prestígio social econômico & 7 & 2,5 \\
\hline Oportunidade no mercado de trabalho & 110 & 38,9 \\
\hline Baixa concorrência por vagas & 2 & 0,7 \\
\hline Outro motivo & 17 & 6,0 \\
\hline Total & 283 & 100 \\
\hline
\end{tabular}

A seguir, procede-se à análise da aquisição de competências pelos alunos formandos.

\section{Percepção pelos alunos da aquisição de competências}

$\mathrm{O}$ item oito do questionário (Apêndice A) compreende as questões relacionadas às competências constantes da LDB, propostas pelas Diretrizes Curriculares Nacionais do curso de Administração (agrupadas em oito categorias). Estas categorias foram subdivididas e transformadas em itens do questionário (Apêndice A).

A primeira análise procedida foi a estatística descritiva das respostas, análise de frequência, mediana e moda (Tabela 4). O nível da escala Concordo Parcialmente (CP-3) foi o resultado comum em 20 das 22 questões (ou diretrizes) constantes no questionário (ou DCN); isto mostra opinião favorável, pelos discentes formandos, quanto à formação das competências apontadas. As questões 14 e 15 tiveram moda 4 e representam o ponto máximo da escala, Concordo Totalmente (CT), mostrando que iniciativa, enfrentar desafios e continuar aprendendo foram competências adquiridas na graduação em Administração. 
Tabela 4: Resultados da estatística descritiva das respostas da pesquisa

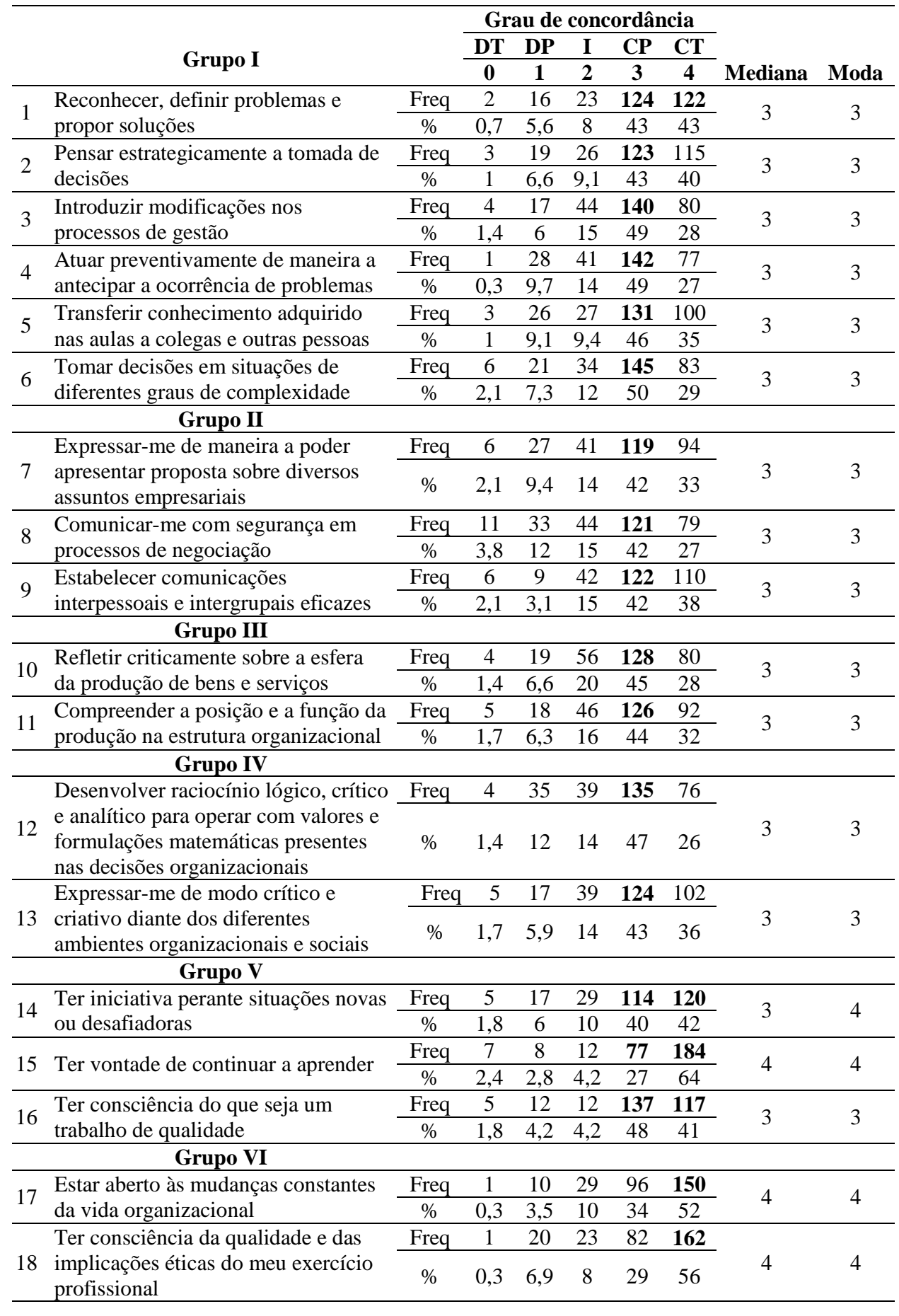




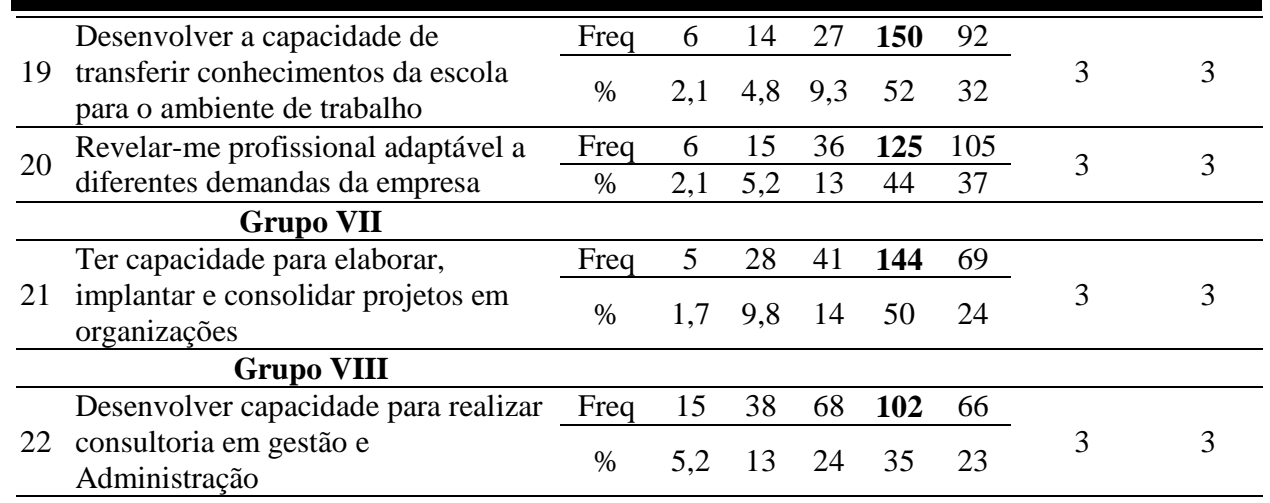

A seguir, são apresentados os resultados da análise realizada por meio de técnicas estatísticas multivariadas.

\section{Resultados da ANÁlise FATORIAL}

A Análise Fatorial foi utilizada para a redução do número de variáveis, agrupando-as em escores de fatores representativos das originais.

As variáveis selecionadas para este agrupamento foram as 22 apresentadas na Tabela 4. Embora a escala utilizada seja ordinal, segundo Steven (1951, 1976), a transformação desta escala em numérica pode levar a resultados frutíferos; para tanto, consideraram-se os valores 0,1 , 2, 3 e 4 para corresponder a Discordo Totalmente, Discordo Parcialmente, Não Concordo Nem Discordo, Concordo Parcialmente e Concordo Totalmente.

Para a aplicação da Análise Fatorial é necessária a normalidade das distribuições. Com este objetivo, foi aplicado o teste KolmogorovSmirnov. Todas as variáveis apresentaram curvas normais no nível de significância de 99,9\%. Em seguida, verificou-se a adequação da técnica por meio de: (1) viabilidade da análise fatorial com base na inspeção da Matriz de Correlação que apresentou 150 correlações superiores a 0,30, representando 64,9\%, em um total de 231 correlações, mostrando que muitas variáveis podem ser agregadas. (2) Teste de esfericidade de Bartlett que mostrou que a matriz de correlações é uma matriz identidade; com nível de confiança de $99,9 \%$, foi rejeitada a hipótese nula de que as variáveis não são correlacionadas conforme apresentado na Tabela 5, indicando que pode haver agrupamento. 
Tabela 5: Teste de esfericidade de Bartlett

\begin{tabular}{lr}
\hline Approx. Chi-Square & 2329,523 \\
\hline DF & 210 \\
\hline Sig. & 0,000 \\
\hline
\end{tabular}

As Correlações parciais foram verificadas com base na Matriz Anti-imagem de correlações que se apresentaram de pequena magnitude, o que demonstra um bom nível de explicação pelos fatores. A análise dos valores de MSA (Measures of Sampling Adequacy) mostrou que nenhuma das 21 variáveis tem valores abaixo de 0,50 (Tabela 6).

Tabela 6: MAS

\begin{tabular}{lclclc}
\hline Variável & MSA & Variável & MSA & Variável & MSA \\
\hline Q16_G5 &, 905 & Q12_G4 &, 931 & Q13_G4 &, 890 \\
\hline Q19_G6 &, 940 & Q5_G1 &, 870 & Q9_G2 &, 886 \\
\hline Q15_G5 &, 875 & Q22_G8 &, 889 & Q8_G2 &, 941 \\
\hline Q11_G3 &, 925 & Q6_G1 &, 891 & Q20_G6 &, 941 \\
\hline Q3_G1 &, 901 & Q2_G1 &, 902 & Q7_G2 &, 911 \\
\hline Q21_G7 & ,916 & Q1_G1 &, 962 & Q14_G5 &, 913 \\
\hline
\end{tabular}

Uma vez verificada a adequação da técnica, foi utilizado o método dos componentes principais. As Comunalidades foram calculadas; de acordo com Hair et al. (2005) comunalidade é a quantia total de variância que uma variável original compartilha com todas as outras incluídas na análise.

Tabela 7: Comunalidades

\begin{tabular}{lclclc}
\hline Variável & Extração & Variável & Extração & Variável & Extração \\
\hline Q16_G5 &, 503 & Q12_G4 &, 573 & Q13_G4 &, 636 \\
\hline Q19_G6 &, 575 & Q5_G1 &, 716 & Q9_G2 &, 614 \\
\hline Q15_G5 &, 623 & Q22_G8 &, 624 & Q8_G2 &, 530 \\
\hline Q11_G3 &, 543 & Q6_G1 &, 574 & Q20_G6 &, 620 \\
\hline Q3_G1 &, 553 & Q2_G1 &, 531 & Q7_G2 &, 619 \\
\hline Q21_G7 &, 552 & Q1_G1 &, 503 & Q14_G5 &, 632 \\
\hline
\end{tabular}

Houve a ocorrência de uma variável com comunalidade inferior a 0,50 (Q18_G6) que foi então retirada. A técnica foi aplicada novamente com as variáveis remanescentes, exceto as variáveis Q4_G1 e Q17_G6, que foram retiradas e os dados foram reprocessados (Tabela 7). 
Tabela 8: Variância Total Extraída: Principal Component Analysis

Initial Eigenvalues Extraction Sums Rotation Sums of of Squared Squared Loadings Loadings

\begin{tabular}{cccccc}
\hline Total & $\begin{array}{c}\text { \% Var. } \\
\text { Acumul. }\end{array}$ & Total & $\begin{array}{c}\text { \% Var. } \\
\text { Acumul. }\end{array}$ & Total & $\begin{array}{c}\% \text { Var. } \\
\text { Acumul. }\end{array}$ \\
\hline 6,974 & 38,746 & 6,974 & 38,746 & 3,138 & 17,431 \\
\hline 1,354 & 46,267 & 1,354 & 46,267 & 3,024 & 34,230 \\
\hline 1,153 & 52,670 & 1,153 & 52,670 & 2,796 & 49,763 \\
\hline 1,040 & 58,445 & 1,040 & 58,445 & 1,563 & 58,445 \\
\hline
\end{tabular}

Para reconhecer os códigos das variáveis, leia-se Q16 ou Q19, questão número 16 ou 19; seguido de G5 ou G6, grupo 5 ou grupo 6 da DCN (Tabela 4). Atenção para não se basear pelo questionário (Apêndice A), pois as questões estão embaralhadas.

Um dos resultados da aplicação do método é o Eigenvalue que representa a quantia de variância explicada por um fator (HAIR et al., 2005, p. 90). O número de fatores foi definido por aqueles com Eigenvalue maior ou igual a 1; foram selecionados os fatores de 1 a 4 apresentados na Tabela 8.

Tabela 9: Matriz Rotacionada

\begin{tabular}{lcccc}
\hline \multirow{2}{*}{ Variável } & \multicolumn{4}{c}{ Componente } \\
\cline { 2 - 5 } & 1 & 2 & 3 & 4 \\
\hline Q22_G8 &, 748 &, 124 &, 018 &, 221 \\
Q6_G1 &, 668 &, 310 &, 125 &, 127 \\
Q2_G1 &, 621 &, 300 &, 142 &, 187 \\
Q21_G7 &, 588 &, 177 &, 418 &,- 009 \\
Q3_G1 &, 534 &, 069 &, 506 &, 082 \\
Q1_G1 &, 487 &, 400 &, 308 &, 104 \\
\hline Q20_G6 &, 330 &, 703 &, 132 &, 015 \\
Q9_G2 &,- 051 &, 679 &, 267 &, 282 \\
Q7_G2 &, 419 &, 646 &, 135 &, 085 \\
Q14_G5 &, 383 &, 632 &, 294 &,- 027 \\
Q13_G4 &, 031 &, 587 &, 230 &, 487 \\
Q8_G2 &, 407 &, 570 &, 177 &, 089 \\
\hline Q15_G5 &, 037 &, 184 &, 766 &,- 008 \\
Q19_G6 &, 175 &, 173 &, 666 &, 267 \\
Q11_G3 &, 188 &, 160 &, 663 &, 204 \\
Q16_G5 &, 164 &, 249 &, 638 &, 085 \\
\hline Q5_G1 &, 158 &, 186 &, 096 &, 805 \\
Q12_G4 &, 398 &, 008 &, 263 &, 587 \\
\hline
\end{tabular}


A interpretação dos fatores é simplificada pela identificação das variáveis que apresentam cargas maiores. Para minimizar o número de variáveis que têm altas cargas em um fator e com isto facilitar a interpretação dos fatores, foi efetuada a rotação pelo método Varimax. Os escores fatoriais foram calculados pelo método de estimação Regression.

Conforme apresentado na Tabela 9, as variáveis contempladas pelos fatores de 1 a 4 são as questões relacionadas nos Quadros 2, 3, 4 e 5 , respectivamente, com nomeação dos fatores em Capacidade de gestão, Habilidade relacional, Conhecimento e Orientação.

Quadro 2: Questões componente do Fator 1 - Capacidade de Gestão

\begin{tabular}{ll}
\hline Q22_G8 & $\begin{array}{l}\text { Desenvolver capacidade para realizar consultoria em gestão e } \\
\text { administração }\end{array}$ \\
\hline Q6_G1 & Tomar decisões em situações de diferentes graus de complexidade \\
\hline Q2_G1 & Pensar estrategicamente a tomada de decisões \\
\hline Q21_G7 & $\begin{array}{l}\text { Ter capacidade para elaborar, implantar e consolidar projetos em } \\
\text { organizações }\end{array}$ \\
\hline Q3_G1 & Introduzir modificações nos processos de gestão \\
\hline Q1_G1 & Reconhecer, definir problemas e propor soluções \\
\hline
\end{tabular}

Quadro 3: Questões componente do Fator 2 - Habilidade Relacional

\begin{tabular}{ll}
\hline Q20_G6 & Revelar-me profissional adaptável a diferentes demandas da empresa \\
\hline Q9_G2 & Estabelecer comunicações interpessoais e intergrupais eficazes \\
\hline Q7_G2 & $\begin{array}{l}\text { Expressar-me de maneira a poder apresentar proposta sobre diversos } \\
\text { assuntos empresariais }\end{array}$ \\
\hline Q14_G5 & Ter iniciativa perante situações novas ou desafiadoras \\
\hline Q13_G4 & $\begin{array}{l}\text { Expressar-me de modo crítico e criativo diante dos diferentes ambientes } \\
\text { organizacionais e sociais }\end{array}$ \\
\hline Q8_G2 & Comunicar-me com segurança em processos de negociação \\
\hline
\end{tabular}

Quadro 4: Questões componente do Fator 3 - Conhecimento

\begin{tabular}{llll}
\hline Q15_G5 & Ter vontade de continuar a aprender; & \\
\hline Q19_G6 & $\begin{array}{l}\text { Desenvolver a capacidade de transferir conhecimentos da escola para o } \\
\text { ambiente de trabalho; }\end{array}$ \\
\hline Q11_G3 & $\begin{array}{l}\text { Compreender a posição e a função da produção na estrutura } \\
\text { organizacional; }\end{array}$ \\
\hline Q16_G5 & Ter consciência do que seja um trabalho de qualidade. & \\
\hline
\end{tabular}

Quadro 5: Questões componente do Fator 4 - Orientação

\begin{tabular}{ll}
\hline Q5_G1 & Transferir conhecimentos adquiridos nas aulas a colegas e a outras pessoas \\
\hline Q12_G4 & $\begin{array}{l}\text { Desenvolver raciocínio lógico, crítico e analítico para operar com valores } \\
\text { e formulações matemáticas presentes nas decisões organizacionais. }\end{array}$ \\
\hline
\end{tabular}


Observa-se uma similaridade dos resultados obtidos com os que foram observados por Godoy e Forte (2007) e Godoy et al. (2009).

Fator 1 - Capacidade de gestão: Esse fator contempla a capacidade de tomar decisões, de pensar estrategicamente, de elaborar e implantar projetos, desenvolvendo um raciocínio crítico e analítico. Tal capacidade apresenta proximidade com a Competência Técnico-profissional, constatada por Godoy e Forte (2007) e de Godoy et al. (2009).

Fator 2 - Habilidade relacional: Envolve a capacidade do aluno de se comunicar, ter iniciativa, de se expressar e de se adaptar a novas situações. Tal fator se assemelha ao de Competência de comunicação, verificado no trabalho de Godoy e Forte (2007) e Competências básicas nos estudos de Godoy et al. (2009).

Fator 3 - Conhecimento: Refere-se à capacidade de compreensão da função produção, ter consciência do que seja um trabalho de qualidade, continuar a aprender e transferir conhecimento da escola para o ambiente de trabalho. É possível fazer uma relação entre esse fator e a Competência Solução de problemas, obtida no estudo de Godoy e Forte (2007) e de Godoy et al. (2009).

Fator 4 - Orientação: Refere-se à capacidade de ensinar e aplicar conhecimento e desenvolver raciocínio crítico, lógico e analítico. Tal fator se assemelha ao de Competência social, verificado no trabalho de Godoy e Forte (2007) e de Godoy et al. (2009).

Após análise fatorial exploratória, foi feita análise por Regressão Logística Binária, que, segundo Hair et al. (2005), é uma técnica multivariada utilizada para aferição da probabilidade da ocorrência de um evento e para a identificação das características dos elementos pertencentes a cada categoria estabelecida pela dicotomia da variável dependente (variável grupo); seus resultados, não satisfatórios são apresentados a seguir.

\section{REGRESSÃo LOGÍSTICA}

Para execução da Regressão Logística Binária, a variável dependente é binária e as variáveis independentes consideradas neste estudo são métricas. Considerou-se como variável dependente binária o Gênero definindo-se dois grupos: Masculino e Feminino e, como variáveis independentes os quatro fatores resultantes da Análise Fatorial.

Não foi necessário testar a normalidade das variáveis independentes porque o impacto é pequeno se a condição não for 
satisfeita. Foi utilizado o método stepwise e o critério Forward: Wald para as primeiras observações.

A significância estatística destes resultados foi verificada pela qualidade de ajuste do modelo por meio das estatísticas Cox \& Snell $\mathrm{R}^{2}$, Nagelkerke $R^{2}$ e "pseudo" $R^{2}$. As estatísticas Cox \& Snell $R^{2}$, Nagelkerke $\mathrm{R}^{2} \mathrm{e}$ "pseudo" $\mathrm{R}^{2}$ comparam as probabilidades previstas com as observadas e o valor mínimo é 0 , que indica nenhum ajuste, e o valor máximo é 1, que indica ajuste perfeito. Os valores $\mathrm{R}^{2}$ das três estatísticas ficaram abaixo de 0,100 mostrando um fraco ajuste.

A Regressão Logística foi reaplicada considerando como variáveis independentes os 4 fatores calculados na Análise Fatorial e como variável dependente Idade, Semestre matriculado, se o respondente trabalha ou não e exercício de atividade remunerada. Porém, as estatísticas dos ajustes das Regressões Logísticas não apresentaram resultado significativo e, por isso, não são apresentadas.

Este resultado representa que o panorama analítico alcançado com análise descritiva e fatorial exploratória não possui variações segundo os grupos amostrais separados por gênero, idade, semestre matriculado e exercício da atividade remunerada. Sendo assim, seguem-se as considerações finais.

\section{CONSIDERAÇõEs Finais}

Este estudo surgiu do questionamento se as instituições de ensino superior (IES), na percepção dos alunos, têm conseguido desenvolver os conhecimentos, habilidades e atitudes sugeridas pelas diretrizes curriculares, durante o curso de graduação.

Em busca de informações que pudessem dar possíveis indicações sobre esta resposta, cinco IES localizadas em diferentes estados foram analisadas. Foram obtidos 289 questionários respondidos, sendo 162 de duas IES do Estado de SP, 91 representam as respostas de outras duas IES do estado de MG e 36 é a quantidade de respostas do Estado de SC. A consolidação da pesquisa demonstrou que o público de formandos do curso de Administração de Empresas de 2006 destas cinco IES são jovens, com idade entre 20 e 25 anos principalmente; há uma divisão equilibrada entre os gêneros masculino e feminino, bem como entre aqueles que fizeram cursinho preparatório para ingressar na graduação. A grande maioria dos respondentes exerce atividade remunerada, o que não é espantoso em se tratando de cursos noturnos, na maioria; o motivo pela 
escolha do curso de Administração divide-se entre a obtenção de oportunidade no mercado de trabalho, aptidão pessoal e relação com o trabalho atual.

Quanto às questões relacionadas ao objetivo deste trabalho, que foi investigar, na perspectiva dos alunos, se as competências e habilidades propostas pelas Diretrizes Curriculares Nacionais (DCN) para os cursos de Administração de Empresas foram desenvolvidas durante o curso de graduação, as repostas da análise descritiva (Tabela 4) mostram alto grau de concordância nos oito grupos de competências proposta pela DCN.

Já os resultados da análise fatorial não confirmam o agrupamento das questões em oito grupos, mas sim, em quatro fatores responsáveis pela explicação de 58,5\% da variância total (Tabela 8). Isto demonstra que os alunos percebem sua formação de maneira mais genérica e abrangente, resumindo-se à Capacidade de gestão, à Habilidade relacional, ao Conhecimento e à Orientação. Este resultado pode sugerir que a expectativa das diretrizes curriculares nacionais para a formação dos graduandos em Administração de Empresas esteja superior à percebida pelos discentes formandos. Outra interpretação se dá pela percepção superficial do ambiente de trabalho pelos alunos, futuros Administradores, onde perceberão suas reais competências na prática, quando do exercício da função da administração empresarial.

Cabe destacar, contudo, que competência é uma inteligência prática, aplicada às situações reais, que se apoia em conhecimentos adquiridos, os quais se transformam na medida em que as ações são desenvolvidas (ZARIFIAN, 2003). Nesse sentido, é importante ponderar que as competências dos administradores, compreendendo o desenvolvimento do conhecimento, habilidades e atitudes, só poderão, de fato, ser verificadas nas situações cotidianas, exercidas no mercado de trabalho. Sugere-se aprofundamento, com a utilização do método qualitativo, procurando identificar o grau de intensidade de aquisição das competências percebidas como desenvolvidas pelos acadêmicos dos cursos de graduação em Administração.

Finalizando, constata-se que a pesquisa contribuiu para esclarecer que, sob a percepção dos discentes, as IES têm conseguido desenvolver competências sugeridas pelas diretrizes curriculares nacionais, especialmente aquelas relacionadas à capacidade do aluno de se comunicar, de se expressar e de se adaptar a novas situações. No entanto, a análise fatorial aponta que a expectativa das diretrizes curriculares nacionais para a formação dos graduandos em Administração de Empresas deve ser superior à percebida pelos discentes formandos. Para 
que estes alunos percebam e de fato desenvolvam plenamente todos ou pelo menos grande parte dos aspectos presentes na DCN, acredita-se que as IES precisarão incorporar em suas práticas, de forma sistemática e estruturada, o currículo voltado para o desenvolvimento de tais competências. Cabe destacar, porém, que, além desta realidade ainda não ter sido incorporada plenamente pelas universidades, conforme sugerem Nunes e Barbosa (2003) e Nunes, Ferraz e Barbosa (2004), os alunos precisam perceber o desenvolvimento efetivo do grupo de competências sugeridas pelas DCN para os cursos de Administração, não se restringindo às habilidades relacionais, como evidencia o resultado desta pesquisa.

Para tanto, será necessário que as IES se preocupem em entender este desafio e estejam abertas para desenvolver estratégias de ensino inovadoras, na busca do que se constitui um "saber fazer", ou seja, para que caminhem em direção à ação sendo precedida de treinamento intensivo capaz de produzir o exercício efetivo dos conhecimentos, habilidades e atitudes, de maneira transversal, que permitam enfrentar conjuntos de situações simples ou complexas, conforme sugere Perrenoud (1999).

\section{REFERÊNCIAS}

BABBIE, E. Métodos de pesquisa de survey. Belo Horizonte: UFMG, 1999.

BITENCOURT, C. C.; KLEIN, M. J. Desenvolvimento de competências: a percepção dos egressos do curso de graduação em administração. In: XXXI Encontro Nacional dos Programas de Pós-Graduação em Administração - EnANPAD, 2007, Rio de Janeiro. Anais... Rio de Janeiro: Anpad, 2007.

COÊLHO, I. M. Graduação: rumos e perspectivas. Revista da rede de avaliação institucional da educação superior, v. 3, n. 9, p. 9-19, set. 1998.

CONSELHO NACIONAL DE EDUCAÇÃO. Câmara de Educação Superior. Resolução $n^{\circ} 1$ de 13 de julho de 2005. Institui as Diretrizes Curriculares Nacionais do Curso de Graduação em Administração, Bacharelado, e dá outras providências. Disponível em: http://portal.mec.gov.br. Acesso em: 03/04/2007.

DOZ, Y. L. Managing core competency for corporate renewal: Towards a managerial theory of core competencies. INSEAD: Corporate Renewal 
Initiative, 1994.

FLEURY, A.; FLEURY, M. T. L. Estratégias Empresariais e Formação de Competências. São Paulo: Atlas, 2001.

GIL, A. C. Técnicas de pesquisa em economia e elaboração de monografias. 3.ed. São Paulo: Atlas, 2000.

GODOY, A. S.; SANTOS, N. J.; FORTE, D.; CARVALHO FILHO, A. F.; GHOBRIL, A. N.; MASMO, P. L. Competências adquiridas durante os anos de graduação: um estudo de caso a partir das opiniões de alunos formandos de um curso de Administração de Empresas. In: XXIX Encontro Nacional dos Programas de Pós-Graduação em Administração EnANPAD, 2005, Brasília. Anais... Brasília: Anpad, 2005.

GODOY, A. S.; FORTE, D. Competências adquiridas durante os anos de graduação: um estudo de caso a partir das opiniões de alunos formandos de um curso de administração de empresas. Gestão \& Regionalidade, v. 23, n. 68, p. 56-69, 2007.

GODOY, A. S.; ANTONELLO, C. S.; BIDO, D. S.; SILVA, D. O desenvolvimento das competências de alunos formandos do curso de Administração: um estudo de modelagem de equações estruturais. Revista de Administração de Empresas, v. 44, n. 3, p. 265-278, 2009.

HAIR J. F.; ANDERSON, R. E.; TATHAN, R. L.; BLACK, W. C. Análise de Dados Multivariados. Porto Alegre: Bookman, 2005.

LEVY-LEBOYER, C. Gestión de las competencias. Barcelona: Gestión 2000, 1997.

MALHOTRA, N. K. Pesquisa de marketing: uma orientação aplicada. 3.ed. Porto Alegre: Bookman, 2001.

MARTINS, G. A. Manual para elaboração de monografias e dissertações. 2.ed. São Paulo: Atlas, 1994.

NICOLINI, A. O futuro administrador pela lente das novas Diretrizes Curriculares: cabeças "bem-feitas" ou "bem-cheias"?. In: XXVI Encontro Nacional dos Programas de Pós-Graduação em Administração EnANPAD, 2002, Salvador. Anais... Salvador: Anpad, 2002.

NUNES, S. C.; BARBOSA, A. C. Q. A inserção das competências no curso de graduação em Administração: um estudo em universidades brasileiras. In: XXVII Encontro Nacional dos Programas de Pós- 
Graduação em Administração - EnANPAD, 2003, Atibaia. Anais... Atibaia: Anpad, 2003.

NUNES, S. C.; FERRAZ, D. M., BARBOSA, A. C. Q. Organização curricular e acadêmica dos cursos de graduação em administração - Uma investigação da adoção do conceito de competências em faculdades de Belo Horizonte, Minas Gerais. In: XXVIII Encontro Nacional dos Programas de Pós-Graduação em Administração - EnANPAD, 2004, Curitiba. Anais... Curitiba: Anpad, 2004.

PERRENOUD, P. Construir as competências desde a escola. Porto Alegre: Artes Médicas Sul, 1999.

PERRENOUD, P. A Competência essencial da corporação. In: ULRICH, D. (Org.). Recursos Humanos Estratégicos. São Paulo: Futura, 2000.

PERRENOUD, P. Dez novas competências para ensinar. Porto Alegre: Artes Médicas Sul, 2000.

PRAHALAD, C.K.; HAMEL, G. Competindo pelo futuro. Rio de Janeiro: Campus, 1995.

RUAS, R. Desenvolvimento de competências gerenciais e a contribuição da aprendizagem organizacional. In: FLEURY, M. T.; OLIVEIRA, Jr. M. (Org.). Gestão estratégica do conhecimento. São Paulo: Atlas, 2001.

SANDBERG, J. Human competence at work. Gotebork: BAS, 1994.

STEVEN, S. S. Mathematics, Measurement and Psychophysics. In Handbook of Experimental Psychology .New York: Wiley, p.1-30, 1951.

STEVEN, S. S. Matemáticas Y Medición. In: WAINERMAN, C. H. (Compil.). Escalas de Medición en Ciencias Sociales. Buenos Aires: Ediciones Nueva Visión S.A.I.C., p.15-74, 1976.

ZARIFIAN, P. Objetivo competência: por uma nova lógica. São Paulo: Atlas, 2001.

ZARIFIAN, P. O modelo da competência: trajetória histórica, desafios atuais e propostas. São Paulo: SENAC, 2003. 


\section{Apêndice A: Questionário da Pesquisa}

Prezado(a) Aluno(a),

Esta pesquisa tem o objetivo de identificar quais das competências propostas pelas Diretrizes Curriculalres dos cursos de Administração de Empresas, listadas abaixo, foram desenvolvidas por você durante o curso de graduação. A pesquisa faz parte da disciplina Ensino em Administração do programa de doutorado da Universidade Presbiteriana Mackenzie e a mesma será aplicada em 4 universidades.

Não há necessidade de se identificar.

Contando com a sua colaboração.

Atenciosamente,

\begin{tabular}{|l|}
\hline 1. Gênero \\
\hline ( ) Masculino \\
( ) Feminino
\end{tabular}

\begin{tabular}{|l|}
\hline 3. Onde cursou o Ensino Médio \\
\hline ( ) Escola Pública \\
( ) Escola Particular \\
\hline
\end{tabular}

5. Motivo predominante da escolha do curso

( ) Relação com o trabalho atual

( ) Aptidão pessoal

( ) Prestígio social/ econômico

( ) Oportunidade no mercado de trabalho

( ) Baixa concorrência por vagas

( ) Outro motivo:

( ) Outro motivo:

\begin{tabular}{|c|c|c|c|c|c|}
\hline \multirow{2}{*}{$\begin{array}{l}\text { 8. Durante o meu curso de } \\
\text { graduação aprendi a: }\end{array}$} & \multicolumn{2}{|c|}{ Discordo } & \multirow{2}{*}{$\begin{array}{c}\text { Não Concordo } \\
\text { Nem } \\
\text { Discordo } \\
\end{array}$} & \multicolumn{2}{|c|}{ Concordo } \\
\hline & Totalmente & $\begin{array}{l}\text { Parcial- } \\
\text { mente }\end{array}$ & & $\begin{array}{l}\text { Parcial- } \\
\text { mente }\end{array}$ & Totalmente \\
\hline $\begin{array}{l}\text { 1) Ter consciência do que seja } \\
\text { um trabalho de qualidade }\end{array}$ & & & & & \\
\hline $\begin{array}{l}\text { 2) Desenvolver a capacidade de } \\
\text { transferir conhecimentos da } \\
\text { escola para o ambiente de } \\
\text { trabalho }\end{array}$ & & & & & \\
\hline $\begin{array}{l}\text { 3) Ter vontade de continuar a } \\
\text { aprender }\end{array}$ & & & & & \\
\hline $\begin{array}{l}\text { 4) Compreender a posição e a } \\
\text { função da produção na estrutura } \\
\text { organizacional }\end{array}$ & & & & & \\
\hline
\end{tabular}

\begin{tabular}{|l|}
\hline 2. Idade \\
\hline ( ) Menos de 20 anos \\
( ) De 26 a 30 anos \\
( ) De 20 a 25 anos \\
( ) Mais de 30 anos \\
\hline
\end{tabular}

4. Fez cursinho preparatório para entrar na Faculdade ou Universidade?

( ) Sim ( ) Não

6. Exercício de atividade remunerada

( ) Não exerce

( ) Parcial (até 30 horas/semana)

( ) Trabalho eventual

( ) Integral (31 horas ou mais)

7. Em qual semestre está matriculado

( ) $7^{\circ}$ semestre

( ) $8^{\circ}$ semestre 
5) Introduzir modificações nos

processos de gestão

6) Ter capacidade para elaborar, implantar e consolidar projetos em organizações

7) Atuar preventivamente de maneira a antecipar a ocorrência de problemas

8) Desenvolver raciocínio lógico, crítico e analítico para operar com valores e formulações matemáticas presentes nas decisões organizacionais

9) Transferir conhecimentos adquiridos nas aulas a colegas e a outras pessoas

10) Desenvolver capacidade para realizar consultoria em gestão e administração

11) Tomar decisões em situações de diferentes graus de complexidade

12) Pensar estrategicamente a tomada de decisões

13) Ter consciência da qualidade e das implicações éticas do meu exercício profissional

14) Reconhecer, definir problemas e propor soluções

15) Estar aberto as mudanças constantes da vida organizacional

16) Expressar-me de modo crítico e criativo diante dos diferentes ambientes organizacionais e sociais

17) Estabelecer comunicações interpessoais e intergrupais eficazes

18) Refletir criticamente sobre a esfera da produção de bens e serviços

19) Comunicar-me com segurança em processos de negociação

20) Revelar-me profissional adaptável a diferentes demandas da empresa

21) Expressar-me de maneira a poder apresentar proposta sobre diversos assuntos empresariais

22) Ter iniciativa perante situações novas ou desafiadoras 


\section{DADOS DOS AUTORES}

MARTA FABIANo SAMBIASE LOMBARDI (martasl@ mackenzie.br)

Doutora em Administração de Empresas pela UPM

Instituição de vinculação: Universidade Presbiteriana Mackenzie

São Paulo/SP - Brasil

Áreas de interesse em pesquisa: Estratégia; relações interorganizacionais; cooperação; valores humanos e sustentabilidade.

LUCIANA TRAVERSO (luciana.traverso@ufsm.br)

Doutora em Administração de Empresas pela UPM

Instituição de vinculação: Universidade Federal de Santa Maria

Silveira Martins/RS - Brasil

Áreas de interesse em pesquisa: Aprendizagem Organizacional; Competências Organizacionais e Gestão do conhecimento organizacional.

RAMON SILVA LEITE (ramons1@ pucminas.br)

Doutor em Administração de Empresas pela UPM

Instituição de vinculação: Pontifícia Universidade Católica de Minas Gerais

Belo Horizonte/MG - Brasil

Áreas de interesse em pesquisa: Ensino e Pesquisa em Administração, Marketing.

Francisval de Melo CaRvalho (francarv@ dae.ufla.br)

Doutor em Administração de Empresas pela UPM

Instituição de vinculação: Universidade Federal de Lavras

Lavras/MG - Brasil

Áreas de interesse em pesquisa: Finanças estratégicas; Medidas de desempenho; Visão Baseada em Recursos.

ABRÃo CARo (abraocar@usp.br)

Doutor em Administração pela FEA/USP

Instituição de vinculação: Universidade Presbiteriana Mackenzie

São Paulo/SP - Brasil

Áreas de interesse em pesquisa: Ensino e Pesquisa em Administração; Marketing.

Recebido em: 14/04/2010 • Aprovado em: 23/01/2011 